\title{
Static Stress Drop in the 1994 Northridge, California, Aftershock Sequence
}

\author{
by Jeanne L. Hardebeck and Egill Hauksson
}

\begin{abstract}
We use time-domain pulse widths to estimate static stress drops for 279 $M_{L} 2.5$ to 4.0 aftershocks of the 17 January $1994, M_{W} 6.7$ Northridge, California, earthquake. The stress drops obtained range from 0.02 to 40 bars, with a log average of 0.75 bar. Error bars computed for our estimates are typically a factor of 5 , indicating that the three order of magnitude scatter in stress drops is not solely a result of measurement errors and that there is a significant amount of heterogeneity in the static stress drops of the aftershocks. Stress drops might be expected to increase with depth, since a fault can maintain a higher shear load at higher confining pressures. We observe an increase in log average stress drop at about $15 \mathrm{~km}$ depth, which is statistically significant at the $80 \%$ confidence level. The increase is due primarily to a lack of lower stress-drop events below this depth and may be controlled by material properties since the Northridge aftershocks are observed to intersect an anomalously high-velocity body at around this depth (Hauksson and Haase, 1997). An apparent increase in stress drop with magnitude is also observed over the entire magnitude range of the study, although whether this trend is real or an artifact of attenuation of high frequencies in the upper crust is unresolved.
\end{abstract}

\section{Introduction}

In this study, we calculate static stress drops for $279 M_{L}$ 2.5 to 4.0 aftershocks following the 17 January $1994, M_{W}$ 6.7 Northridge earthquake (Hauksson et al., 1995). We are primarily interested in whether stress drop increases with depth. One might expect that since higher confining stresses allow rock to bear higher applied stresses, rock at depth could fail in higher stress-drop events. Higher stress drops for deeper events have been reported in several studies (e.g., Jones and Helmberger, 1996; Song and Helmberger, 1997), while other studies report a lack of such a trend (e.g., Mori et al., 1996). The Northridge sequence is a particularly useful data set for investigating stress-drop variations with depth since the aftershocks extend to deeper than $20 \mathrm{~km}$. We also address whether or not stress drop appears to increase with magnitude.

\section{Data and Method}

We study 279 Northridge aftershocks (Fig. 1) that were located using the three-dimensional southern California velocity model of Hauksson and Haase (1997) and arrival times from Southern California Seismic Network (SCSN) stations. Events in the $M_{L} 2.5$ to 4.0 range are used in estimating static stress drops because the seismograms of smaller events may not have clear arrivals and those of larger events are likely to be complicated by source complexity and directivity effects. The aftershocks were selected for clarity of recordings of the initial $P$-wave pulse.
Static stress drop, $\Delta \sigma$, is calculated from a relation for a circular fault (Brune, 1970):

$$
\Delta \sigma=7 M_{0} / 16 r^{3}
$$

where $r$ is the radius of the fault and $M_{0}$ the seismic moment.

Moment can be estimated from local magnitude, $M_{L}$, from an empirical relationship for southern California earthquakes (Thatcher and Hanks, 1973):

$$
\log M_{0}=1.5 M_{L}+16.0
$$

with $M_{0}$ in dyne-cm. The slope constant in equation (2) appears to be slightly greater than 1.5 for the Northridge aftershock sequence when the long-period moments of $M_{L} 4.0$ to 5.6 events are determined from waveforms (Song and Helmberger, 1997). Because we are primarily interested in relative moments and relative stress drops, however, a discrepancy in a constant of proportionality should not greatly affect our results.

The radius of a circular fault rupturing uniformly outward from the center is related to the duration of the time function of the rupture, $\tau$, by (e.g., Frankel and Kanamori, 1983; Boatwright, 1980)

$$
r=\frac{\tau \nu}{1-(\nu / \alpha) \sin \theta}
$$



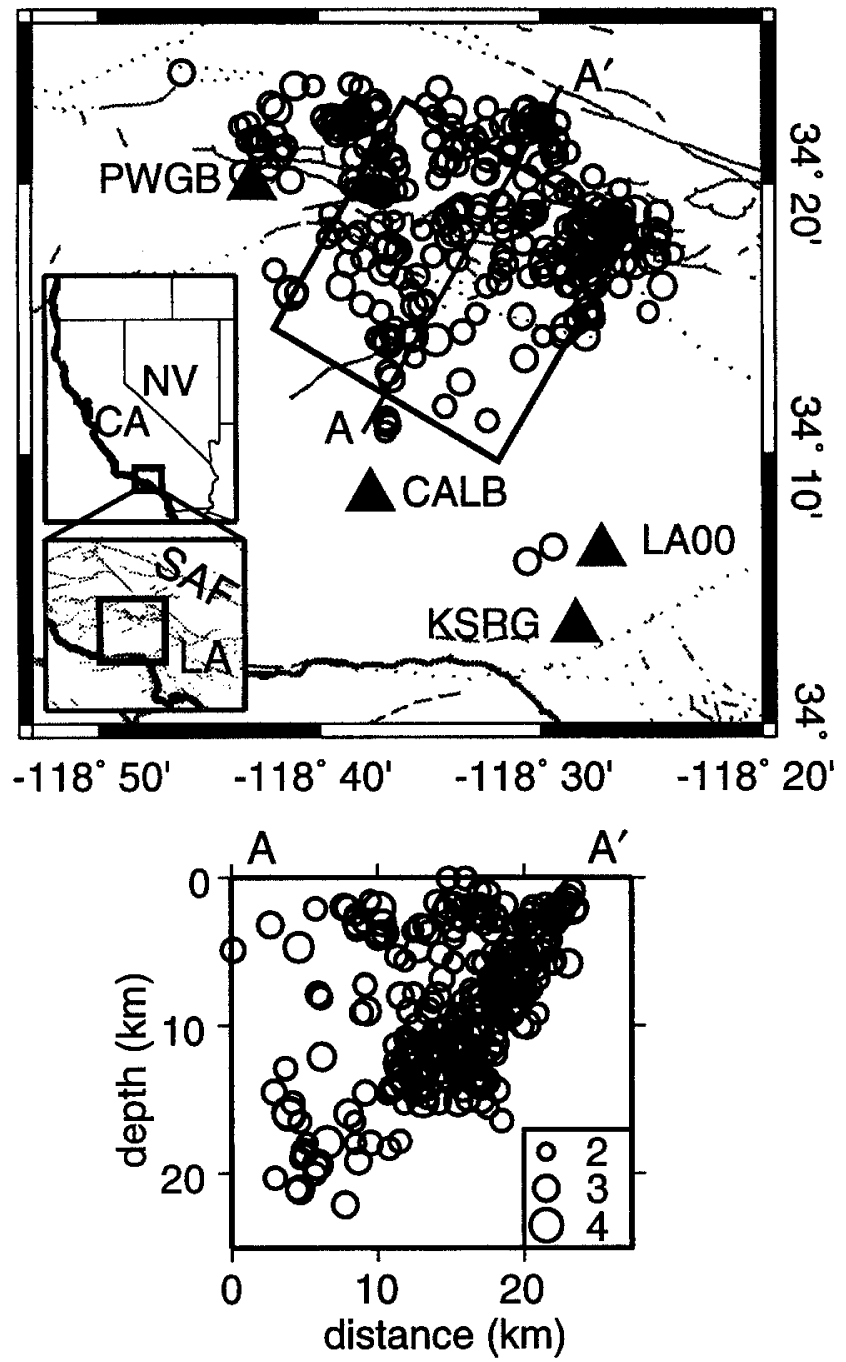

Figure 1. Northridge aftershocks, $M_{L}=2.5$ to 4.0 , used in this study, shown as open circles in map view and in northeast-southwest cross section through the mainshock fault plane. Mainshock fault plane, shown as a black rectangle, from Wald et al. (1996). The stations used in this study are shown as solid triangles.

We use rupture velocity $v=0.9 \beta$ and assume that the $S$ wave velocity, $\beta$, is proportional to the $P$-wave velocity, $\alpha$, by the relation: $\beta=0.6 \alpha$. We use a one-dimensional $P$-wave velocity model (Table 1) adapted from Hauksson and Haase (1997) and Hauksson et al. (1995). The takeoff angle relative to the fault, $\theta$, is arbitrarily set to $45^{\circ}$. Again, because we are examining relative stress drops, uncertainties in the constants used should not significantly affect our results.

Broadband velocity seismograms from the Calabasas TERRAscope station (CALB) and three Southern California Earthquake Center (SCEC) temporary stations (Fig. 1) are used to estimate the rupture duration of an event based on the width of the initial $P$-wave pulse. The azimuthal coverage is not complete due to the sparsity of stations in the mountains to the north and northeast. The seismograms are
Table 1

$P$-Wave Velocity Model

\begin{tabular}{cc}
\hline $\begin{array}{c}P \text {-Wave } \\
\text { Velocity }(\mathrm{km} / \mathrm{sec})\end{array}$ & $\begin{array}{c}\text { Depth to Top } \\
\text { of Layer }(\mathrm{km})\end{array}$ \\
\hline 3.5 & 0 \\
4.5 & 1 \\
5.0 & 2 \\
5.5 & 6 \\
6.0 & 8 \\
6.5 & 12 \\
6.6 & 16 \\
6.72 & 18 \\
\hline
\end{tabular}

bandpass filtered between 0.4 and $40 \mathrm{~Hz}$. The width of the initial $P$-wave pulse is measured on the vertical component of clean non-nodal records, measuring from the emergence of the signal from the background noise to the first zero crossing. There appears to be a general broadening of the average pulse with hypocentral distance, presumably due to attenuation of high frequencies. The increase in pulse width appears to be approximately $1.6 \mathrm{e}^{-4} \mathrm{sec} / \mathrm{km}$ hypocentral distance. We correct for this trend by subtracting $1.6 \mathrm{e}^{-4} \mathrm{sec} / \mathrm{km}$ distance from each pulse width. A station correction is also applied, so that the mean rupture duration for the entire data set is the same at each station.

The corrected rupture durations are in the range of 0.024 to $0.34 \mathrm{sec}$, and the corresponding fault radii are in the range of 0.13 to $1.3 \mathrm{~km}$. From the estimated source size and moment, we determine the static stress drop for each event as observed from each station, and we determine a combined estimate by averaging these values in log domain. The combined estimates of stress drop range from 0.02 to 40 bars, with a log average of 0.75 bar (Fig. 2). This is a wide, but reasonable, range of values.

The stress-drop calculation is clearly most sensitive to the estimation of rupture duration, since, in equation (1), $\Delta \sigma$ goes as $1 / r^{3}$, and hence as $1 / \tau^{3}$. It is therefore important to determine if the wide range of $\Delta \sigma$ values obtained is an artifact of uncertainties in the measurement of $\tau$. Our measurements of $\tau$ are generally consistent across the four stations, usually to within $0.05 \mathrm{sec}$, and the stress drop as observed from each station is usually within a factor of 3 of the combined stress-drop estimate for that event (Fig. 3). An order of magnitude difference in stress drop can correspond to a visible difference in pulse width. Both events shown in Figure 4 have $M_{L}=2.9$ and are approximately $24 \mathrm{~km}$ from the station LA00 where they are recorded. The event in the top record has a longer observed $P$-wave pulse at this station, about $0.15 \mathrm{sec}$, while the event in the lower record has a shorter pulse, about $0.05 \mathrm{sec}$. The lower record clearly has greater high-frequency content than the upper record. When stress drops are combined for all stations, the stress drop of the first event is about $0.5 \mathrm{bar}$, and that of the second is about 6 bar. This evidence suggests that not all of the scatter in $\Delta \sigma$ 


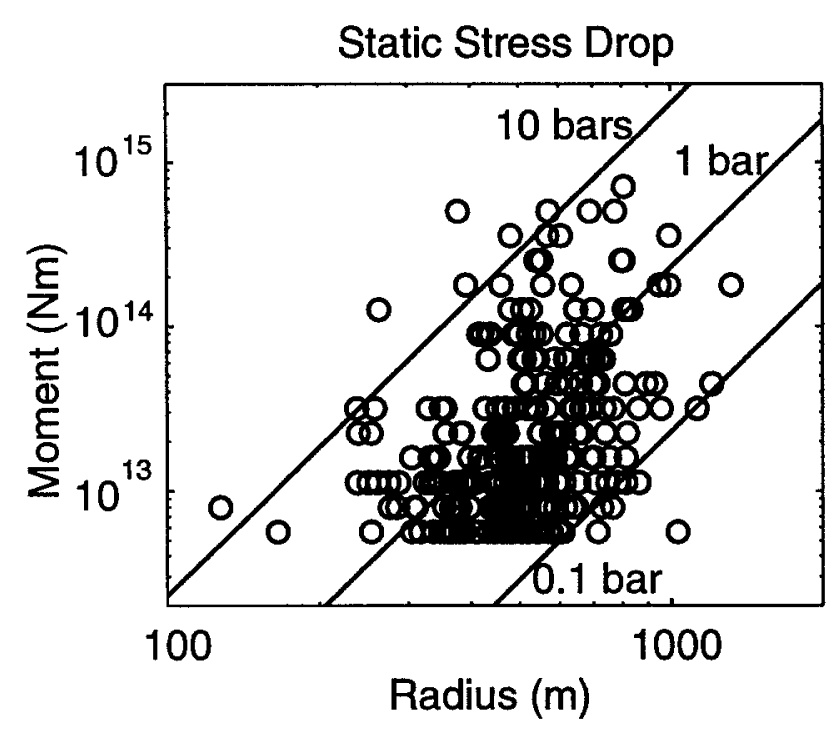

Figure 2. The combined (all stations) static stressdrop estimates for the Northridge aftershocks, shown on a plot of seismic moment versus rupture radii. The solid diagonal lines are contours of constant static stress drop.

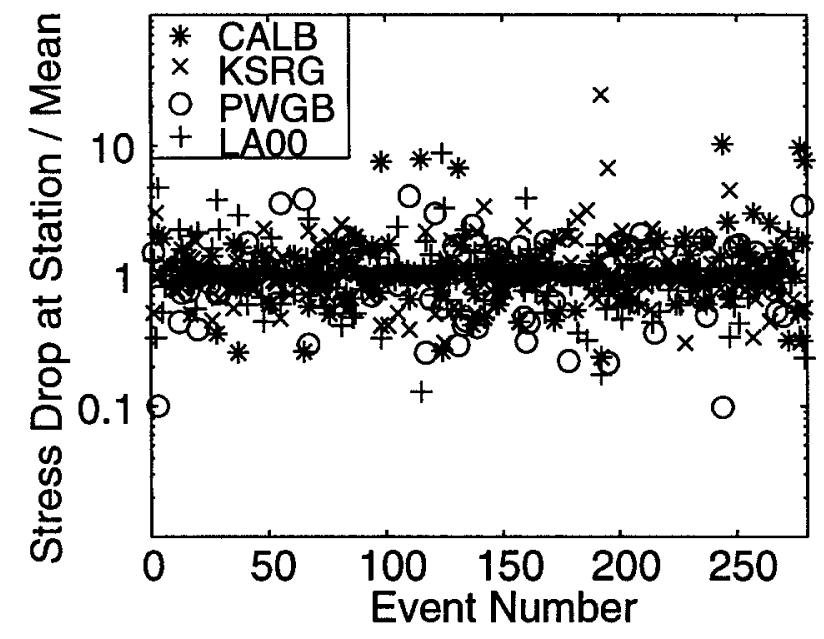

Figure 3. The ratio of static stress drop as observed at a station to the combined static stress-drop estimate for each event. The observations from different stations have different symbols.

estimates comes from uncertainty in $\tau$, as further supported by a quantification of measurement uncertainty.

Measurement error bars are computed for the stress drops as observed at each station. The measurement error of event magnitude is taken to be 0.05 magnitude unit. The digital seismogram sample spacing, $0.0125 \mathrm{sec}$ for CALB and $0.005 \mathrm{sec}$ for the SCEC temporary stations, is used as the pulse width measurement error. These values are used to determine a maximum and a minimum stress-drop estimate for each event at each station, which define the measurement error bars.
There are two kinds of uncertainties that go into the error bar for the combined static stress-drop estimate: measurement uncertainty as previously described and uncertainty due to the differences between the observations at each station. The later uncertainty can be characterized as the $95 \%$ confidence interval for the mean:

$$
\pm 1.96 \frac{\sigma}{\sqrt{N}}
$$

where $\sigma$ is the standard deviation of the observations at individual stations and $N$ is the number of stations for which recordings were used. The measurement uncertainty can be written analogously, if we think of the measurement error bar as a $95 \%$ confidence interval that should narrow with an increasing number of measurements:

$$
\pm m / \sqrt{N}
$$

where $m$ is the mean measurement error. We calculate these two $95 \%$ confidence intervals in the log domain and combine them to determine the $95 \%$ confidence interval for the average static stress drop:

$$
\pm \sqrt{\frac{(1.96 \sigma)^{2}+m^{2}}{N}}
$$

Most of these error bars are less than a factor of 5, indicating that measurement uncertainty is not responsible for the three orders of magnitude scatter in stress-drop estimates. It appears, then, that there is a significant amount of actual scatter in the static stress drops of the aftershocks. This is not surprising, considering the heterogeneous state of stress in the region (e.g., Wilde and Stock, 1997).

\section{Observations}

The combined static stress-drop estimates for the aftershocks, along with error bars, are shown versus magnitude in Figure 5. There are several orders of magnitude scatter in most magnitude ranges, but static stress drop increases with magnitude over the entire magnitude range of our data with a correlation coefficient of 0.7 . It is possible that this relationship may be an artifact of our method, since $\Delta \sigma$ as calculated in equation (1) depends on $M_{0}$. If $M_{0}$ were overestimated for large events and underestimated for small ones, that is, if the slope constant in equation (2) were too large, an increase in stress drop with magnitude would be observed. This is probably not the case, however, since the work of Song and Helmberger (1997) suggests that, if anything, the constant we use is too low.

In Figure 6, static stress drop, along with error bars, is shown versus depth. There is much scatter in the estimates in all depth ranges. However, the static stress-drop estimates 


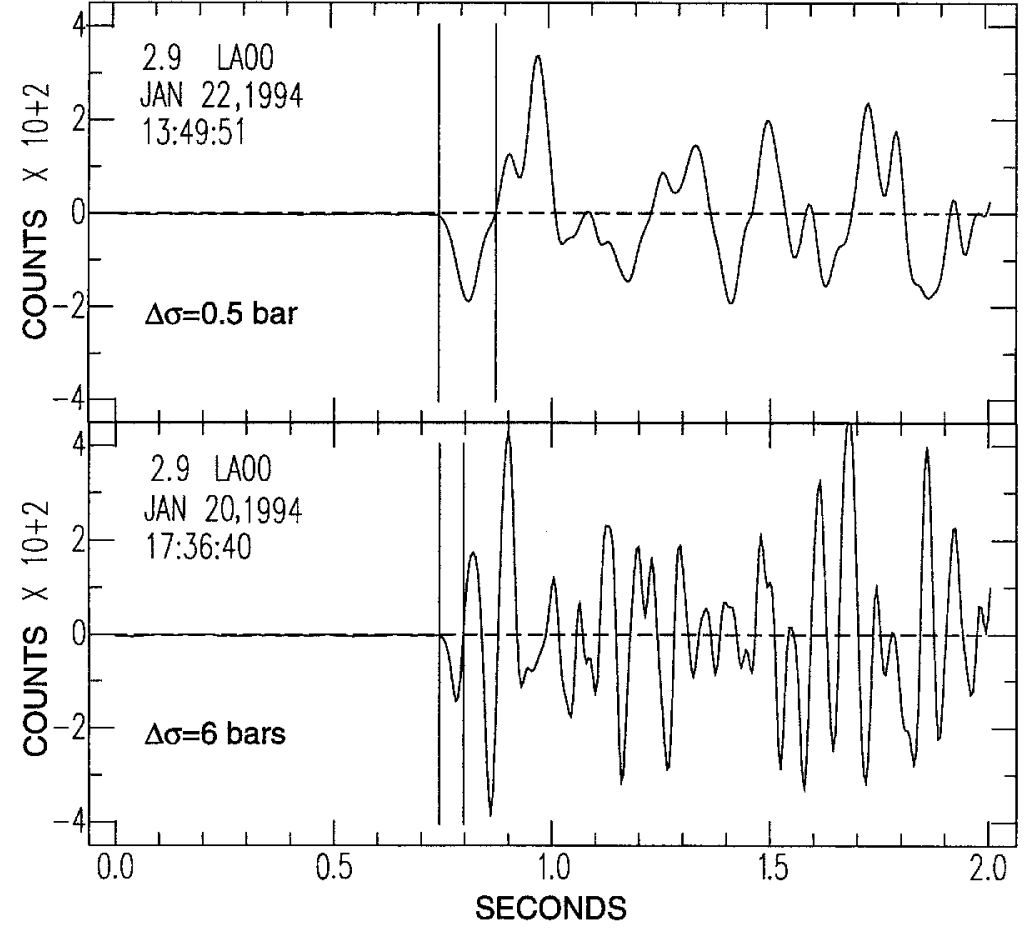

Figure 4. Velocity records of the $P$ waves, recorded at the station LA00, of two events with the same magnitude and epicentral distance $\left(M_{L}=2.9\right.$, distance $\left.=24 \mathrm{~km}\right)$. The event in the top record has a longer corrected $P$-wave pulse, about $0.15 \mathrm{sec}$, and a calculated static stress drop of about $0.5 \mathrm{bar}$, while the event in the lower record has a shorter pulse, about $0.05 \mathrm{sec}$, and a stress drop of about 6 bars.

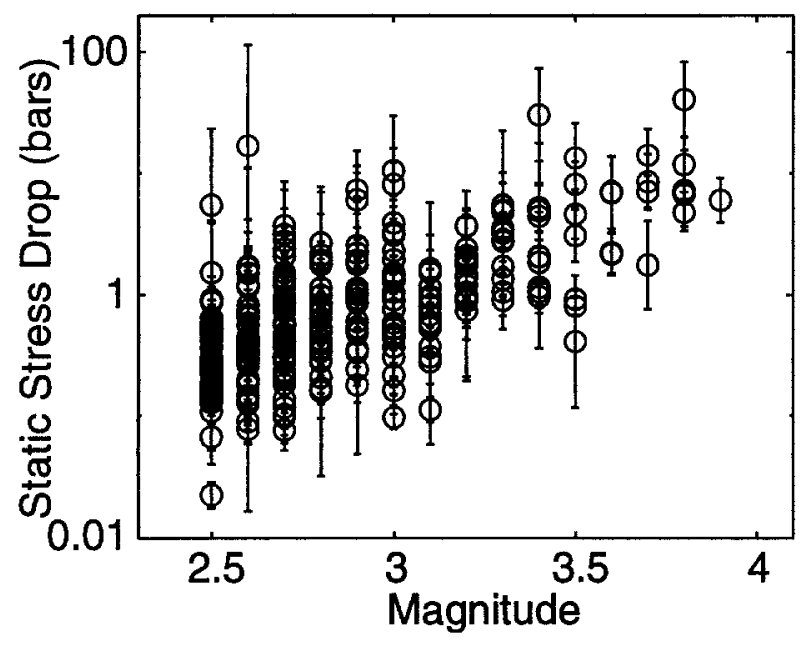

Figure 5. Combined estimates of static stress drop versus magnitude, with error bars.

for the shallowest and deepest events appear relatively low and high, respectively.

Shallow events, less than $2 \mathrm{~km}$ depth, have lower stress drops, generally less than 1 bar. We perform a Student's $t$ test in order to determine if the difference between the mean stress drops (in the log domain) of 0- to 2-km-deep and 2to $15-\mathrm{km}$-deep events is statistically significant, following the methodology of Press et al. (1986) for distributions with possibly different variances. We modify the standard error (SE) in order to incorporate the typical standard deviation (SD) of the stress-drop estimate uncertainty.

$$
\mathrm{SE}(\text { modified })=\sqrt{\mathrm{SE}^{2}+\mathrm{SD}^{2}} .
$$

We find that the difference between the means is not statistically significant. The null hypothesis, that the $\Delta \sigma$ estimates for the two sets of events come from populations with the same mean, cannot be rejected at the $80 \%$ confidence level.

Deeper than about $15 \mathrm{~km}$, the observed stress drops appear higher. Again we test for statistical significance using a Student's $t$-test. This time we find that we can reject the null hypothesis; that is, the static stress drops of events at depths between 2 and $15 \mathrm{~km}$ and at depths greater than 15 $\mathrm{km}$ come from populations with the same mean, at the $80 \%$ confidence level. We therefore consider the difference in $\Delta \sigma$ estimates between events deeper and shallower than $15 \mathrm{~km}$ to be statistically significant. This difference is primarily due to an increase in the lowest observed stress drops. This phenomenon is most pronounced for the observations at CALB (Fig. 6a) and LA00 (Fig. 6d), although it is seen at all stations. Below about $15 \mathrm{~km}$ depth, low stress-drop events ( $<0.3$ bars) appear to be "missing." This is probably not due to a bias in data selection, since deep events in this magnitude range should have clean seismograms regardless of stress drop. The deeper events are not of higher magnitude, so this observation is not due to the higher estimated stress drops of larger events.

\section{Discussion}

The rupture durations found here for $M_{L} 2.5$ to 4.0 aftershocks of the Northridge earthquake, ranging from 0.024 to $0.34 \mathrm{sec}$, are comparable to rupture durations of 0.035 to $0.143 \mathrm{sec}$ found for $M_{L} 2.3$ to 4.0 events in New England (Feng and Ebel, 1996). The estimated static stress drops, ranging from 0.02 to 40 bars, are comparable to the 0.5 to 
(a) CALB

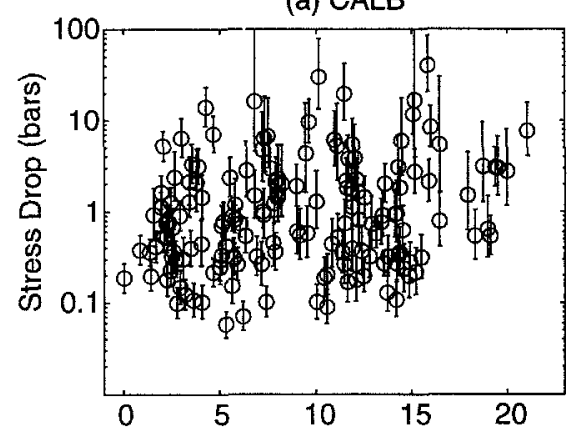

(c) PWGB

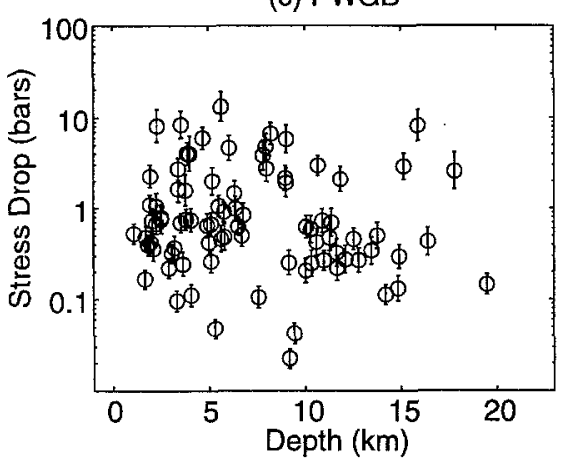

(b) KSRG

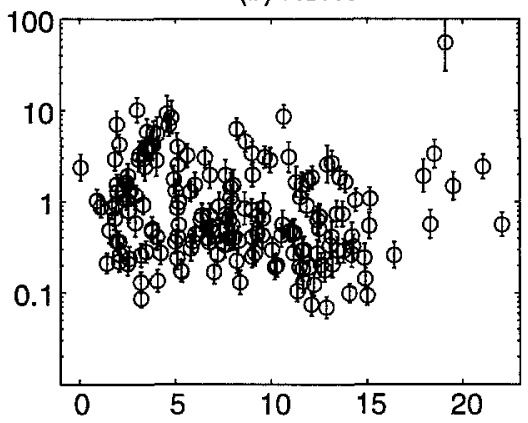

(d) LA00

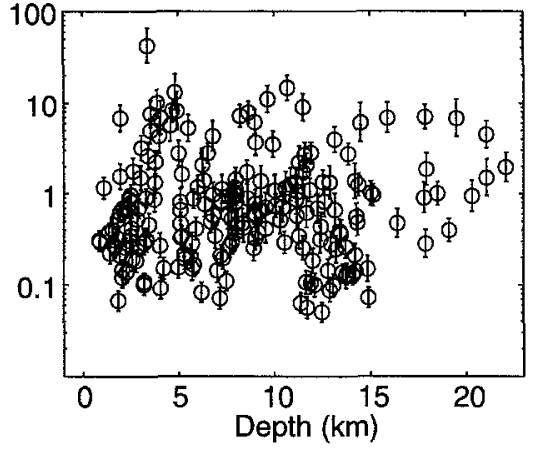

(e) Combined Estimate

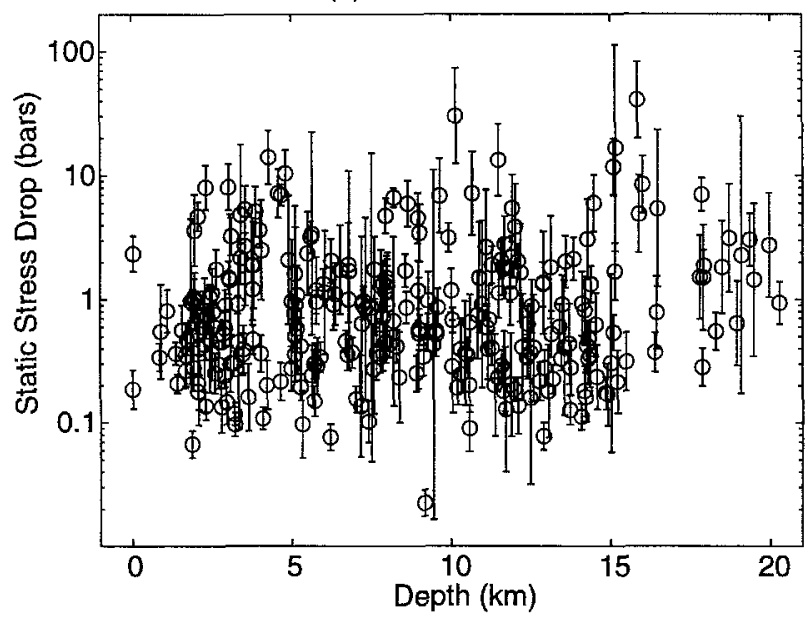

Figure 6. Static stress drop versus depth, with error bars. (a)-(d) Observations at individual stations. (e) Combined estimate.

80 bar stress drops found for $M_{L} 2.0$ to 3.5 aftershocks of the 1983 Coalinga earthquake (Lindley and Archuleta, 1992). However, these stress drops are significantly lower than those found in some other studies of similar-sized southern California earthquakes. For instance, Frankel and Kanamori (1983), who use a similar method for estimating stress drops, find an average stress drop of 170 bars, greater than any stress drops seen here. Abercrombie and Leary (1993) and Abercrombie (1995) compile stress drops for events over a large range of magnitudes, and those with $M_{W}$ of about 2.5 to 4.0 have stress drops ranging from about 5 to 1000 bars. There are several possibilities for this differ- ence. One is that our method may be leading to a systematic overestimate of rupture duration and dimension. Another is that our results may be more accurate, given that we are using modern broadband digital data, unavailable at the time of Frankel and Kanamori's (1983) study, as well as for some of the studies complied by Abercrombie and Leary (1993) and Abercrombie (1995). A third possibility is that the discrepancy reflects a difference between earthquakes that are part of an aftershock sequence (i.e., our events) and those that are not [i.e., the background seismicity analyzed by Frankel and Kanamori (1983)].

We observe an increase in stress drop with magnitude 
for $M_{L} 2.5$ to 4.0 Northridge aftershocks. The same trend has also been reported for $M>4$ Northridge aftershocks (Mori et al., 1996). Other studies, however, have determined that stress drop does not vary with magnitude over large ranges of magnitude (Abercrombie and Leary, 1993; Abercrombie, 1995). There are several proposed explanations for an observed trend in stress drop with magnitude. Mori et al. (1996) suggest that it indicates that more energetic earthquakes tend to grow to be larger-magnitude events. It has also been suggested that there is a minimum nucleation size of earthquakes, causing small-magnitude events to have low stress drop since they cannot rupture a smaller area. The observation of Archuleta et al. (1982), that stress drop increases with magnitude only for $M<3$ events, is consistent with this model. This theory does not explain why the trend of increasing stress drop with magnitude would continue for larger events, as it does for $M>4$ Northridge aftershocks (Mori et al., 1996). Abercrombie and Leary (1993) and Abercrombie (1995) suggest that the apparent lower stress drops and minimum source areas for small events are artifacts of attenuation of high frequencies. It could be that an increase in stress drop with magnitude is not universal but occurs in some circumstances, such as the Northridge sequence, or it may be that our observations have been effected by the attenuation of high frequencies.

An increase in stress drop with depth has been found in previous work. For the Big Bear aftershock sequence, Jones and Helmberger (1996) find that events shallower than 12 $\mathrm{km}$ had stress drops in the range of 10 to 100 bars, averaging about 55 bars, while events deeper than $12 \mathrm{~km}$ had stress drops exceeding 100 bars and averaging 200 bars. Song and Helmberger (1997), studying $M_{L} 4.0$ to 5.6 Northridge aftershocks, find that the highest stress drops occur below 8 $\mathrm{km}$ depth. We also observe higher stress drops for deeper $M_{L} 2.5$ to 4.0 Northridge aftershocks. Specifically, we find a statistically significant increase in stress drop at about 15 $\mathrm{km}$ depth.

At greater depths, the normal stress across a fault is greater, and therefore, the fault could support a greater shear load before failure. When an earthquake occurs, there is more shear stress to be relieved, so one would expect deeper fault patches to be capable of failing in higher stress-drop events. Low stress-drop events could presumably occur at any depth. One would expect, then, to see an increase in maximum observed stress drop with depth, and no change in the minimum observed stress drop. This is what we notice at shallow depths, where the maximum observed stress drops may be increasing at about $2 \mathrm{~km}$ depth. However, at about $15 \mathrm{~km}$ depth, we observe the opposite occur: The minimum observed stress drop increases while the maximum remains essentially unchanged. The lack of increase of maximum observed stress drops with depth may be because stress drop is not strongly controlled by the total stress on the fault. At depths greater than $2 \mathrm{~km}$, stresses observed in boreholes (e.g., Zoback and Healy, 1992) are at least an order of mag- nitude higher than the highest observed aftershock stress drops.

It appears that smaller stress-drop events are inhibited at depth, which is unexpected. The lack of low stress-drop events may be due to the increase in confining stresses, or to a material property change. The Northridge aftershocks below about $15 \mathrm{~km}$ depth appear to occur within a highvelocity ridge (Hauksson and Haase, 1997), indicating that material properties may play an important role. One possible scenario is that only more energetic events are capable of growing to at least $M>2.5$ in stronger materials or under greater stresses.

\section{Conclusions}

We investigate trends in static stress drop with magnitude and depth for 279 aftershocks of the 1994 Northridge earthquake. A trend of increasing stress drop with magnitude is found. We also observe an increase in average stress drop at about $15 \mathrm{~km}$ depth, as lower stress-drop events appear suppressed below this depth. There is evidence that this may be controlled by material properties. Both of these trends are superimposed on approximately three orders of magnitude of scatter in the stress-drop estimates, while measurement errors are around a factor of 5, indicating significant heterogeneity in aftershock stress drops. If it could be shown that the increase in static stress drop with magnitude was an artifact of attenuation of high frequencies in the upper crust, and the trend removed, scatter would probably be closer to two orders of magnitude. Recordings from broadband downhole seismometers, such as those used by Abercrombie (1995) and Abercrombie and Leary (1993), will probably be important in resolving this issue.

\section{Acknowledgments}

We thank Craig Scrivner and David Wald for their helpful comments on an early draft of the manuscript, and reviewers Mark Zoback and Ruth Harris for their suggestions that helped to refocus and greatly improve the article. We thank Lucy K. Jones for housing the CALB TERRAscope station in her garage. This research was partially supported by USGS Grant 143494-G-2440. Contribution Number 5726, Division of Geological and Planetary Sciences, California Institute of Technology. SCEC Contribution Number 337 .

\section{References}

Abercrombie, R. (1995). Earthquake source scaling relationships from -1 to $5 \mathrm{M}_{\mathrm{L}}$ using seismograms recorded at $2.5 \mathrm{-km}$ depth, J. Geophys. Res. 100, 24015-24036.

Abercrombie, R. and P. Leary (1993). Source parameters of small earthquakes recorded at $2.5 \mathrm{~km}$ depth, Cajon Pass, Southern California: implications for earthquake scaling, Geophys. Res. Lett. 20, 15111514.

Archuleta, R. J., E. Cranswick, C. Mueller, and P. Spudich (1982). Source parameters of the 1980 Mammoth Lakes, California, earthquake sequence, J. Geophys. Res. 87, 4595-4607.

Boatwright, J. (1980). A spectral theory for circular seismic sources: simple 
estimates of source dimension, dynamic stress drop, and radiated seismic energy, Bull. Seism. Soc. Am. 70, 1-25.

Brune, J. N. (1970). Tectonic stress and the spectra of seismic shear waves from earthquakes, J. Geophys. Res. 75, 4997-5009.

Feng, Q. and J. E. Ebel (1996). Determination of rupture duration and stress drop for earthquakes in New England, Seism. Res. Lett. 67, 38-51.

Frankel, A. and H. Kanamori (1983). Determination of rupture duration and stress drop for earthquakes in southern California, Bull. Seism. Soc. Am. 73, 1527-1551.

Hauksson, E. and J. S. Haase (1997). Three-dimensional $V_{p}$ and $V_{p} / V_{s}$ velocity model of the Los Angeles basin and central Transverse Ranges, California, J. Geophys. Res. 102, 5423-5453.

Hauksson, E., L. M. Jones, and K. Hutton (1995). The 1994 Northridge earthquake sequence in California: seismological and tectonic aspects, J. Geophys. Res. 100, 12335-12355.

Jones, L. and D. V. Helmberger (1996). Seismicity and stress-drop in the eastern Transverse Ranges, southern California, Geophys. Res. Lett. 23, 233-236.

Lindley, G. T. and R. J. Archuleta (1992). Earthquake source parameters and the frequency dependence of attenuation at Coalinga, Mammoth Lakes, and the Santa Cruz Mountains, California, J. Geophys. Res. 97, 14137-14154.

Mori, J., H. Kanamori, and R. Abercrombie (1996). Scaling of stress drop and energy from Northridge aftershocks (abstract), EOS 77, Fall Meet. Suppl. F481.
Press, W. H., B. P. Flannery, S. A. Teukolsky, and W. T. Vetterling (1986) Numerical Recipes: The Art of Scientific Computing, Cambridge Univ. Press, Cambridge, U.K., 818 pp.

Song, X. J. and D. V. Helmberger (1997). Northridge aftershocks, a source study with TERRAscope data, Bull. Seism. Soc. Am. 87, 1024-1034.

Thatcher, W. and T. C. Hanks (1973). Source parameters of southern California earthquakes, J. Geophys. Res. 78, 8547-8576.

Wald, D. J., T. H. Heaton, and K. W. Hudnut (1996). The slip history of the 1994 Northridge, California, earthquake determined from strongmotion, teleseismic, GPS, and leveling data, Bull. Seism. Soc. Am. 86, S49-S70.

Wilde, M. and J. Stock (1997). Compression directions in southern California (from Santa Barbara to Los Angeles) obtained from borehole breakouts, J. Geophys. Res., 102, 4969-4983.

Zoback, M. D. and J. H. Healy (1992). In situ stress measurements to 3.5 $\mathrm{km}$ depth in the Cajon Pass scientific research borehole: implications of the mechanics of crustal faulting, J. Geophys. Res. 97, 5039-5057.

Seismological Laboratory

California Institute of Technology

Pasadena, California 91125

Manuscript received 1 July 1996. 